\title{
The Impact of Self-Acceptance of stuttering on In-Role Performance by Self-Efficiency: Moderating role of Transformational Leadership
}

\author{
Faiza Iqbal $^{1}$, Madya Yahya Don ${ }^{2}$, Muhammad Dzahir Bin Kasa ${ }^{3}$ \\ ${ }^{1} \mathrm{PhD}$ Scholar, School of Education and Modern Languages, University Utara Malaysia \\ ${ }^{2}$ Professor, School of Education and Modern Languages, University Utara Malaysia \\ ${ }^{3}$ Senior Lecturer, School of Education and Modern Languages, University Utara Malaysia \\ Email: faizaiqbal322@gmail.com
}

\begin{abstract}
The purpose of the study is to examine the impact of self-acceptance of stuttering on in-role performance via self-efficacy by taking transformational leadership as moderator. Total 70 questionnaires (self-administered) distributed to the respondents who are the people who stutter in Rawalpindi and Islamabad, 60 questionnaires were considered useable for the purpose of analysis with $85.7 \%$ response rate and collected the data by using those questionnaires which are consisting of all variables measuring on 5-point Likert scale. Snowball sampling method was used. Correlation and regression analysis were tested by using SPSS for data analysis to check direct, mediating as well as moderating relationship in between the key variables. Results show that self-acceptance of stuttering significantly relates in-role performance. Self-efficacy mediates among stuttering self-acceptance and success inrole.
\end{abstract}

Keywords: Self-Acceptance of Stuttering (SAoS), Self-Efficacy and Transformational Leadership

\section{Introduction}

Self-acceptance of stuttering has been an essential part of stuttering over the years and no published report analyzed or assessed the treatment (De Nardo, Gabel, Tetnowski \& Swartz 2016). Acceptance is highlighted by Sheehan and Martyn (1970) as a basic module of improvement which can be seen from the previous work of experts (Guitar, 2013; Shapiro, 2009) and individuals who stutter (PWS) (Plexico, Manning, \& Levitt, 2009; Wingate, 1964). Stuttering is a condition which hinders a person to speak fluently in daily life circumstances (ASHA, 2009; Daniels, 2008), feelings of embarrassment and social anxiety occurs that damages numerous ways like physically, socially, psychologically (Craig, 2010; Frattali, 
1998; Yaruss \& Quesal, 2004; Yaruss, 2010), also leads to depression (Ardila et al., 1994) and low self-efficacy (Perkins, 1993; Prins, 1993). Stuttering usually starts in childhood with projected occurrence of $1 \%$ worldwide (Craig, Hancock, Tran, Craig, \& Peters, 2002).

Many people demand perfection in work context physically as well as emotionally (Sheane, 2012) with ability to communicate effectively (Van Riper, 1982). Stuttering decreases job performance, employment and promotion opportunities (Hurst \& Cooper, 1983). Although self-acceptance (SA) has also been extensively discovered in autism educations and has been found to be correlated with many cheerful causes, together with improved health results superior life gratification and improved recovery in the literature of stuttering studies, this topic has received limited attention. SAoS is an important aspect of effective stuttering organization (Plexico et al., 2005). Stuttering awareness always has the potential to diminish the need to mask stuttering and the need to be fluent. This facilitates an optimistic, evaluative and direct approach to stuttering by the person (Plexico et al., 2009). When researching disability acceptance, there are many variables to consider, including selfesteem, psychological support, perceived prejudice, and aggression (De Nardo, et al., 2016). Such positive aspects of self-acceptation need more work on factors that can lead to increased SAoS. In this study, we will see the connection of SAoS on In-role performance (e.g. work efficiency) implies a behavior that can be predicted by official system of recompense. When defined in job descriptions, it is part of the specifications. Knowledge and skills are critical inrole performance characteristics (Goodman \& Svyantek, 1999).

Stuttering outcome relates with inability to perform or stop individual to attempt but acceptance of stuttering refers to the acceptance of performing or can-do attitude. This leads to the self-efficacy. Social cognitive theory is built on Bandura's concept of self-efficacy which is defined as an individual's self-assurance in his or her capability to achieve specific responsibilities required to achieve a desired goal (Bandura, 1997). Workplace research shows that self-efficacy improves work commitment and job satisfaction (Xanthopoulou, Bakker, Demerouti \& Schaufeli, 2007; Luthans, Avolio, Avey \& Norman, 2007). Workers who think they can take the necessary actions are more likely to set ambitious targets, to pursue productive work and therefore work better than workers with less control. (Bandura, 2001; Stajkovic \& Luthans, 1998). Self-efficacy is therefore usually considered to be an individual job advantage that corresponds to self-regulation and employee adaptation (Gist \& Mitchell, 1992; Luthans et al., 2007). General self-efficacy and its task or field-specific conceptualizations are generally examined as mediator or moderator variables within 
Pakistan Journal of Humanities and Social Sciences, 7(3), 2019

occupational health psychology research (Nielsen, Yarker, Randall, \& Munir, 2009; Xanthopoulou, Bakker, Demerouti, \& Schaufeli, 2007). The results showed that self-efficacy, social assistance and social functioning have all made a significant contribution to psychological resilience prediction (Boyle, 2015).

Although transformational leadership (TFL) has been found to be related to the attendant's levels of self-efficacy, we suggest that workers who come to comparatively associate with transformative leaders are more effective and thus improve their performance. (Kark, Shamir, \& Chen, 2003). TFL is performance-oriented (Bass, 1985). Relatively few studies have examined the mechanism by which transformative leaders boost the self-efficacy of the attendants (Kark, et. al, 2003, for an exception). Self-efficiency stands to benefit across a number of different efficiency domains (Chen, Casper, \& Cortina, 2001; Stajkovic \& Luthans, 1998; Walumbwa, Avolio, \& Zhu, 2008), this is essential to make people more aware of why the followers of transformational leaders are more self-efficient. We use the principle of relational identity (Sluss \& Ashforth, 2007) to illustrate that TFL increases the self-efficacy of followers. Researchers have now begun to extend their analyses to consider the health-related effects of TFL (Kelloway, \& Barling, 2010). Sosik and Godshalk (2000) found that indirectly, TFL activity forecast lowered work-related stress levels. For example, the available evidence suggests that TFL impacts individual wellbeing through a shift in the expectations of employees of their jobs (Arnold, Turner, Barlig, Kelloway \& McKee, 2007) which improving the TFL behaviours.

As per the latest study of (Rees \& Sabia, 2014) suggested the future direction to check the impact of stuttering on workforce, productivity, occupational choice and earnings. Impact of self-acceptance of stuttering on in-role performance through self-efficacy is an underexplored area especially in the context of Pakistan.

\section{Literature Review}

\section{A. Self-Acceptance of Stuttering and In-Role Performance}

A general concept of self-acceptance by (Carver, Scheier \& Weintraub, 1989) is to what degree one may face the reality of one's painful condition and pursue practical goals. This cycle of self-acceptance is not a passive style of surrender or consent to the situation. It is rather a necessary step of obtaining an agency because he or she will have to understand and face the problem to become his or her own agent. The literature indicates that positive transition and adaptation are distinguished by a person's ability to demonstrate an interest in life development, to consider his personal achievements, to handle negative life experiences 
effectively, improve the environment in order to relieve restrictions and participate in significant actions. The modifications were based on self-acceptation, accountabilities, suitable social tools and the use of positive coping strategies, added by DeLoach and Greer (1981).

We assume that self-acceptance of stuttering increases in-role performance. "Organizational members accomplish their work through roles; these roles are sets of behaviors that persons expect of occupants of a position" (Graen, 1976, p. 1201). Employee role quality in the context of tasks refers to the activities and practices that he or she must conduct to fulfill their own duties in the work stated specifically in job descriptions. Assessments of the job performance of individuals typically describe their behavior in this role (e.g., Griffin, Neal, \& Parker, 2007; Welbourne, Johnson, \& Erez, 1998). Many people demand perfection in work context physically as well as emotionally (Sheane, 2012) with ability to communicate effectively (Van Riper, 1982). PWS also believe that their speech impairment is a vast difficulty for employment (Craig \& Calver, 1991; Klein \& Hood, 2004; Klompas \& Ross, 2004) as well as for job promotion and negatively effects the job performance and compromise on lower level jobs (Craig and Calver, 991; Garcia, Laroche, \& Barette, 2002; Bloodstein \& Bernstein Ratner, 2008; Craig \& Calver, 1991; Klein \& Hood, 2004), therefore job performance decreases with stuttering (Hurst \& Cooper, 1983). However, individual performance increases when employees accept their stuttering disability. Plexico et al. reported that(1) "participants began to develop a broader self-concept that encompassed attributes unrelated to stuttering,", enlarge the values and subordinate the form (stuttering behavior) to several different values (2) contestants began "accepting that stuttering was a 'part of the self' rather than a defining characteristic", demonstrate that the respondents had the condition to describe their personality; and (3) "participants were also able to facilitate greater self-acceptance by viewing stuttering from a different, broader and more positive perspective", proposing that stuttering has been considered an advantage. Disability acceptance is described as an alteration of a person's structure of values so that its real or imagined loss(es) do not adversely affect the quality of established aptitudes or the individual. (Dembo, et al., 1975; Keany \& Glueckauf, 1993). But SAoS has changed the whole scenario and accepted this problem and

Employees feel stuttering as a serious phenomenon at work setting (Craig \& Calver, 1991; Klein \& Hood, 2004). They consider their personalities as having little ability to perform a given job which ultimately results in their low job performance (Klompas \& Ross, 
2004). However, the employees who accept their stuttering, they consider their selves as part of other employees (De Nardo, Gabel, Tetnowski \& Swartz, 2016). Acceptance theory (Dembo et al., 1975) states that people who accept their problems and other disabilities, they tend to learn not only by their mistakes but also learn from other their colleagues. Similarly, employees accept their stuttering, they don't pay attention on this problem. Therefore, they perform well with other employees. Stuttering does not bother them, therefore they compete with other employees to meet the expected job performance which enhance their in role performance (Plexico et al, 2009 b).

Hypothesis 1: Self-Acceptance of Stuttering is positively associated with in-role performance.

\section{B. Mediating role of Self-Efficacy between Self-Acceptance of stuttering and In-role Performance}

Self-efficacy is people's faith in their ability to perform a mission with trust and accomplish a goal (Bandura, 1977). Scales designed to assess self-efficacy primarily emphasize the faith and confidence of individuals in their own competence (Chen, Gully, \& Eden, 2001; in this context, competence is used synonymously with self-efficacy). Selfefficacy has been recognized by various theories as an important indicator of performance results (e.g., goal-setting theory, Locke, 199; social learning theory, Bandura, 1977). Stuttering was directly associated with lower self-efficacy (Perkins, 1993; Prins, 1993). Selfacceptance is a possible factor; it implies all facets of self-acceptance (Rogers \& Carmichael, 1942). Folkman (1997) proposed that seeking meaning can elicit positive feelings even in adverse situations and highlighted the importance of positive feelings in promoting psychological well-being. Therefore, self-acceptance is an undesirable behavior that helps individuals endorse and console themselves in uncomfortable situations (Kim, 2008) by recognizing and accepting both benefits and drawbacks of themselves, even in unpleasant situations. These self-acceptance features may reinforce the association between life sense and adjusting to life.

The fluency disorder which is commonly known as 'stuttering' starts from childhood and influence the large number of people in the society (Craig, Hancock, Tran, Craig, \& Peters, 2002). Stuttering is an involuntary disruption in the speech fluency via blocking of sounds, substitution and words' avoidance (Bloodstein, Bernstein \& Ratner, 2008). Involuntary in nature, the stuttering seriously disturbed the emotional as well as mental health of employees (Menzies, Onslow, \& Packman, 1999; Craig \& Tran, 2006). However, the 
employees who self-accept this stuttering, they show a belief that they can control or minimize the stuttering problem, try to openly speak like other employees without hesitation. They regard it as natural phenomena, therefore its increases their 'can do' belief and they perform better like other workers at work setting (Bray, Kehle, Lawless \& Theodore, 2003). We believe that self-efficacy catalyzes the association between stuttering and in role performance. Self-acceptance of stuttering is means coping with this disorder. In selfacceptance of stuttering, employees try to constantly change the cognitive as well as behavioural efforts to manage external demands of performance. With this self-acceptance, their self-efficacy increases and they performance as required in the organization (Lazarus \& Folkman, 1984).

The association between SAoS and self-efficacy can be clarified in the sense of cognitive evaluation theory. The theory of social cognitive argues that self-efficacy is a controlled mechanism that directs the actions of the employee towards different results. (Bandura, 1997; 2001). Social cognitive theory explores factors that increase the self-efficacy of workers and describe self-efficacy as a human agency psychological mechanism. Bandura additional explained this: "Unless anyone believe that he can cause required results with forestall detrimental with his actions, he has little incentive to act or perhaps to persevere in the face associated with difficulties. Whatever various other points may work Just like guides and motivators, he is rooted with the core belief he has the power to be able to produce effects from one's actions". Self-acceptance of stuttering motivates employees that they can perform the given role and ultimately it increases their ability in role performance. On the basis of above studies, we propose a following relationship.

Hypothesis 2: The relationship between Stuttering self-acceptance and in-role success is mediated by self-efficacy.

\section{Moderating position of Transformational Leadership between Stuttering self- acceptance and self-efficacy}

In this context, Self-efficacy exhibiting individual's willingness to perform a specific task but sometime this self-efficacy needs to be pushed through the role of a leader which is required in the organization because sometime people feel demoralized due to number of factors. Those employees who are usually self-efficient and confident on that day may feel less productive because they will not seek the help of the supervisor they are used to. Specifically, they analyzed whether the daily changes in transformational leadership have an effect on the day-to-day dedication of employees to work through the daily special resources 
of employees. (self-efficacy and optimism) by (Tims, Bakker, Xanthopoulou, 2011). Transformational leadership is considered as leadership conduct that changes workers' standards and values, inspiring the leader to deliver beyond their own desires (Yukl, 1989). This style of leadership aims to improve the participation of supporters with their organization's goals. (Bass, 1985). A key aspect of this style of leadership is the supervisor's inspiring vision (den Hartog, Koopman, \& van Muijen, 1997). The transformation behavior of four types is idealized when leaders do what is right or reasonable rather than a smooth approach and are based on their ethical obligations to their supporters and go beyond the welfares of the organization. Leaders displaying positive inspiration encourage their staff by situation high expectations and speaking a vision of what can be done to accomplish more than was previously thought possible. Leaders that show intellectual stimulation help workers challenge their own generally held beliefs, reframe issues, and innovatively solve issues. Eventually, individual concern arises when leaders pay particular attention to the needs for accomplishment and advancement of workers; they provide the required empathy, sensitivity and encouragement that workers may strive for their well-being. Human concern applies to subordinates being supervised, encouraged and stimulated. The leader understands the feelings and emotions of supporters and their need to develop and grow (Den Hartog et al., 1997). Workers are seen as autonomous individuals who need precise, personal attention in line with their phase of development (Avolio \& Bass, 1995). This type of individual concern is consistent with this study.

The strong correlation observed may indicate that self-esteem is an important component of stuttering acceptance, and thus stuttering management. Future work is important to explore the causes of this relationship. Since SAoS is a new phenomenon and minimal literature is accessible and its relation to transformational leadership in general has not received sufficient research attention in the literature. (De Nardo et al, 2016). We apply information to the literature body. Previous studies showed that emotional support had a significant positive effect on the cycle of recovery and impairment acceptance. For two factors, transformational leadership is expected to improve the self-efficacy of employees. Firstly, suggested by (Shamir, House \& Arthur, 1993) that transformational leaders improve the self-efficacy of their workers by voicing huge expectations for them and their ability to meet certain goals. Second, transformation leaders offer their workers expertise and social persuasion to persuade them of their abilities (Bandura, 1977). The findings showed high and significant quality of life and support for the family. Boyle (2015) further found that social 
support for family members was an important factor in determining quality of life.Social assistance is a broad term for different kinds of aid. It supports emotion, data, evaluation and measuring (Demaray, 2003). Emotional assistance is an act of caring and love, thankfulness and appreciation. (McColl, 1995). The most common way to help relatives and friends is Frequently studied in disability studies because of its strong relationships with acceptance, well-being, improved quality of life and improved psychological results in disability studies.

By using social persuasion, transformational leaders strengthen the expectations of employees about their ability to succeed in a given task (Pajares, 2002); this increases employees ' confidence and self-efficacy. "Empirical studies have confirmed the transformational leadership's on self-efficacy influence. For example, in a laboratory study of 282 students, Kirkpatrick and Locke (1996) explored the relationship between transformative leadership and self-efficacy". Therefore, the following relationship is expected.

Hypothesis 3: Transformational leadership will moderate the relationship between SelfAcceptance of Stuttering and Self-Efficacy, such that the relationship will be stronger for higher transformational leadership than low transformational leadership.

\section{Conceptual Model}

\section{Figure 1}

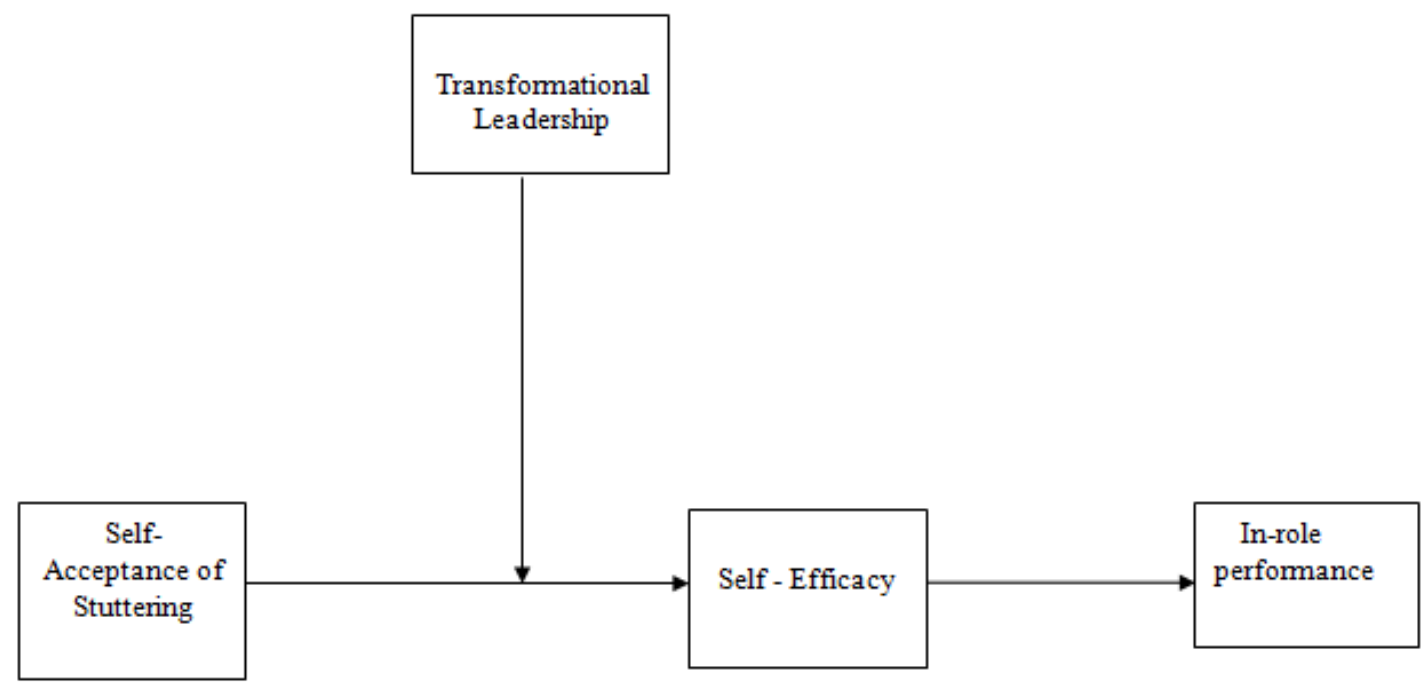

\section{A. Population and Sample}

The sample consisted of stuttering people residing in Rawalpindi/Islamabad. Snow ball sampling technique was used to gather data from respondents. By using snowball sampling method, a total of 60 self-administered questionnaires were filled out from 
Pakistan Journal of Humanities and Social Sciences, 7(3), 2019

respondents who stuttered. Rationale behind the selection of stuttering people was based on the fact that the main author also stutters and intended to check stuttering effects on in-role performance via self-efficacy and to check transformational leadership as moderator between self-acceptance of stuttering and self-efficacy. Eight hospitals were requested to provide access to people who stutter based in Rawalpindi/Islamabad, only two hospitals allowed who have mature stutters rest were dealing with children. In these two hospitals, we met with stuttering respondents one by one on their turn for speech therapy (check-up) and they referred to other respondents. Out of 70 questionnaires, 60 considered useable for analysis with a response rate of $85.7 \%$.

\section{B. Instrumentation}

All sample variables are measured from Strongly Disagree $=1$ to Strongly Accept $=5$ on a Likert 5-point scale.

\section{Scale of Self-Acceptance of Stuttering}

SAoS was measured with an improved version of the Disability Acceptance Scale (AD; Linkowski, 1971). The ten items formed a 50-point scale with higher scores which indicated higher self-acceptance rates. Stuttering stops me from doing things I like is one sample item. The alpha for Cronbach's modified AD scale was.87.

\section{Scale of Self-Efficacy}

Self-Efficacy was measured through General Self-Efficacy Scale as it fits with stuttering behavior. SE was measured using 8-itmes scale developed by tap Eden's (2001). One Sample item is "I will be able to achieve most of the goals that I have set for myself."

\section{Scale of Transformational Leadership}

Transformational Leadership was measured using 6-items scale of individualized consideration attribute developed by Li and Shi's (2005). One sample item is "My immediate supervisor shows concerns for his/her subordinates' personal situations."

\section{Scale of In-Role Job Performance}

We measured In-Role Job Performance self-reported by using Podsakoff and MacKenzie's (1989) five item scale for in-role performance was measured using 5-items scale for in role performance. One sample item is "I always complete the duties specified in my job description." 


\section{Results}

Table 1 provides descriptive statistics and correlations among the principal variables of this analysis. Conceptual framework shows the effects of Stuttering's self-acceptance on InRole performance through Self-Efficacy and Transformational Leadership as Moderator. To test these effects correlation analysis is performed. The matrix shows that there is positive correlation between self-acceptance of stuttering and in-role performance $(r=.350, p<0.000)$, insignificant correlation between self-acceptance of stuttering and self-efficacy $(r=.253, p>$ $0.05)$, positive correlation between self-acceptance of stuttering and transformational leadership $(\mathrm{r}=.340, \mathrm{p}<0.000)$.

Table 1: Means, Standard Deviations, Correlations, and Reliabilities

\begin{tabular}{|c|c|c|c|c|c|c|}
\hline & Mean & S.D & $\mathbf{1}$ & $\mathbf{2}$ & $\mathbf{3}$ & $\mathbf{4}$ \\
\hline 1. SE & 3.60 & 0.64 & $(.81)$ & & & \\
\hline $2 . \mathrm{TL}$ & 3.84 & 0.61 & $.772^{* *}$ & $(.75)$ & & \\
\hline 3. IP & 3.77 & 0.70 & $.628^{* *}$ & $.684^{* *}$ & $(.79)$ & \\
\hline 4.SAS & 3.62 & 0.63 & .253 & $.340^{* *}$ & $.350^{* * *}$ & $(.81)$ \\
\hline
\end{tabular}

$\mathrm{n}=60$, alpha reliabilities are given in parenthesis, **. Correlation is significant at the 0.01 level (2-tailed), *. Correlation is significant at the 0.05 level (2-tailed).

For testing the impact of Self -Acceptance of Stuttering on In-role performance via Self-Efficacy and moderating role of transformational leadership between Self-acceptance of stuttering a regression self-efficacy study was carried out.

\section{A. Mediation of Self-Efficacy between Self-Acceptance of Stuttering and In Role Performance}

A mediation study was performed by Preacher and Hayes using SPSS using PROCESS macro. Model 4 according to Hayes models serves as a system for mediation. The effect of stuttering self-acceptance on role performance can be partitioned into two sections in the mediation standard below (Table 2): 1) the direct effect of stuttering self-acceptance on role performance, and 2) the indirect effect of stuttering self-acceptance on performance of roles through self-efficacy. Combined, the direct and indirect effect of self-acceptance of stuttering on in role performance or the total effect for positive relationships is 0.39 . Hence, hypothesis 1 is accepted which states that self-acceptance of stuttering is positively associated with in role performance. The direct effect of self-acceptance of stuttering on in role performance when the mediator is included in the model it turns out to be 0.23 with a positive sign that indicates a positive relationship between stuttering self-acceptance and role performance. The indirect or mediation effect that is a measure of how much of the effect of 
SAS on IP is mediated turns out to be 0.16 and is significant, with no zero-value lying between the upper and lower confidence interval boot values. Therefore, we accept H2 i.e. self-efficacy mediates the relationship between self-acceptance of stuttering and in role performance.

Table 2: Mediation Analysis

\begin{tabular}{|c|c|c|c|c|}
\hline Effect & Effect Size & S.E & LLCI & ULCI \\
\hline Total Effect & 0.39 & 0.14 & 0.12 & 0.67 \\
\hline Direct Effect & 0.23 & 0.12 & -0.002 & 0.46 \\
\hline Indirect Effect & 0.16 & 0.11 & 0.01 & 0.44 \\
\hline
\end{tabular}

\section{B. Moderation of Transformational Leadership between Self-Acceptance of Stuttering and In Role Performance}

Using PROCESS macro, the results of moderation analysis according to Table 3 show that the improvement in $\mathrm{r} 2$ as a moderator due to transformation leadership turns out to be 0.004 , which is a marginal shift and the outcome does not reflect the value of 0.83 in any meaningful way. Furthermore, we assume that transformational leadership does not stabilize between self-acceptance and self-efficacy in stutters and therefore, H3 is not recognized. For greater clarity a plot of moderation is also provided.

Table 3: Moderation Analysis

\begin{tabular}{|c|c|c|}
\hline $\mathrm{R}^{2}$ Change & $\mathrm{F}$ & Sig \\
\hline 0.0004 & 0.05 & 0.83 \\
\hline
\end{tabular}

Figure 2: Moderation Plot of Transformational Leadership between Stuttering self-acceptance and self-efficacy

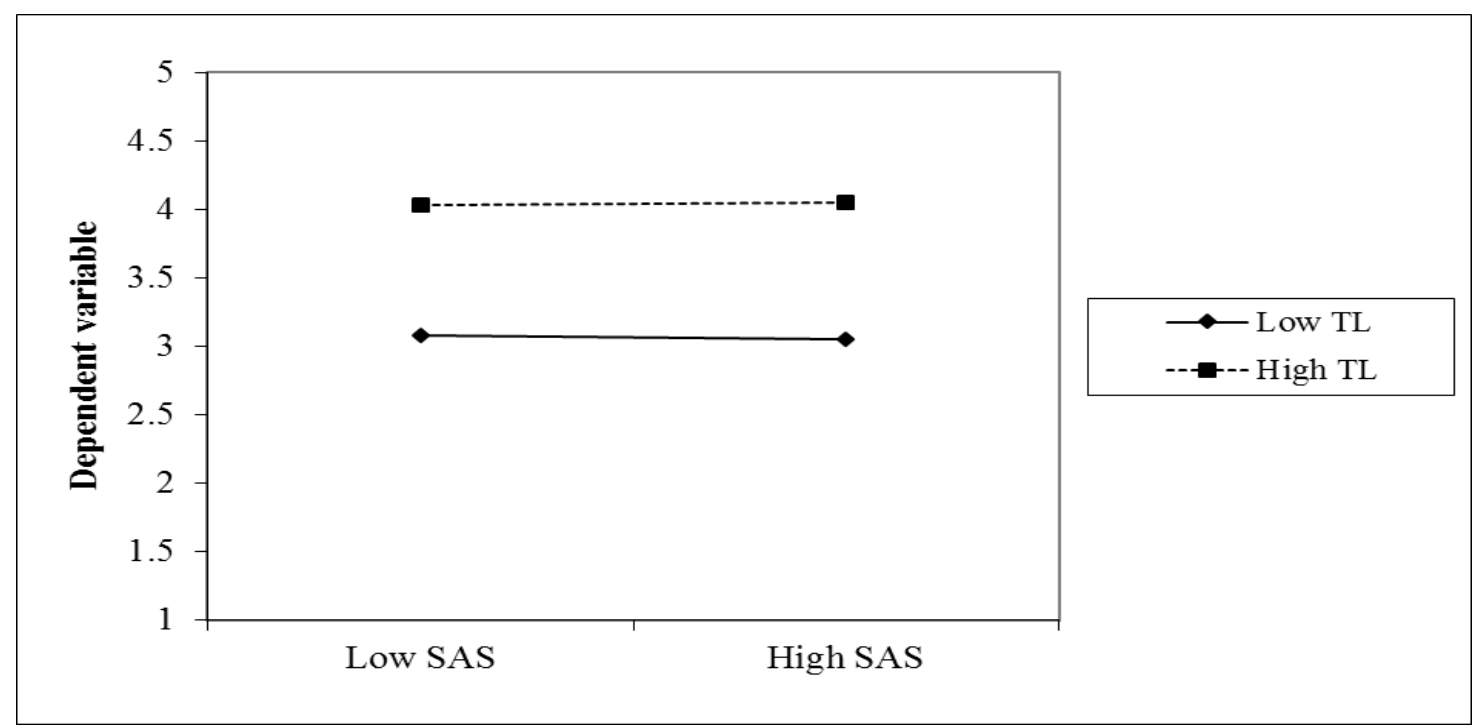




\section{Discussion}

The main purpose and objective of this study was to scrutinize the connection of SAoS with in role performance via self-efficacy and to check the transformational leadership between SAoS and self-efficacy. In general, out of 3 hypotheses, this study confirms two hypotheses on the basis of literature review and logic based. "Disadvantages experienced by an individual, resulting from the stuttering impairment and associated disabilities, or from reactions to them (exhibited either by the individual or by those with whom the individual interacts) that limit the individuals' ability to fulfill social, occupational, or economic roles that would otherwise be considered normal and attainable for that individual" (Yaruss, 1998). SAoS was identified as an important element in effective stuttering management and correlated with higher standard of living (Swartz, Irani, \& Gabel, 2014). SAoS can diminish the desire to defend stuttering and the expectation that it will always be expressed. It allows people to view stuttering in a constructive, evaluative and direct manner. (Plexicoetal.,2009 a, 2009 b;Swartz et al.,2014).

The result of this study shows that the self-acceptance of stuttering people has accepted their disability and willing to use their true potential. Most of the stutters believe that their self-acceptance of stuttering does not interferes with their in-role performance. Here in this case, hypothesis 1 was positively associated with in role performance and this hypothesis accepted based on total effect i.e. 0.39. The main reason for this is the acceptance of disability. The results revealed that hypothesis $\mathrm{H} 2$ i.e. self-efficacy mediates the relationship between stutter's self-acceptance and role success that is in line with the reviewed literature and the logical arguments provided in this report. The final section of our hypothesis was focused on testing the moderating role of transformational leadership between Stuttering SelfAcceptance (IV) and Self-Efficacy. In this context, this is the unique model of my study to test the relationship of self-acceptance of stuttering with in role performance via self-efficacy by taking transformational leadership as moderator between self-acceptance of stuttering and self-efficacy. As hypothesized in hypothesis 3 that transformational leadership will moderate the relationship between self-acceptance of stuttering and self-efficacy such that the relationship will be stronger for higher transformational leadership than low transformational leadership. Results indicate that in hypothesis 3, there is no significant moderation between self-acceptance of stuttering and self-efficacy, hence rejected hypothesis. As this hypothesis was based on the logical arguments, but not proved true mainly because of role of transformational leadership is different upon people with self-acceptance of stuttering as 
compared with those of normal people or employee in an organization. There is a need to study this with more respondents as the data was very limited. In general, out of 3 hypotheses, this study confirms two hypotheses on the basis of literature review and logical arguments.

\section{Practical Implications for Managers}

This study has some implications for managers. Firstly, managers must be aware about the human resource practices and workplace environment for those people having disabilities as well as hindrances which may occur during the course of job done. Stuttering also hinders one's ability to say what he/she intends to say. Manager may create a work environment which provides the equal opportunities as well as those aspects which relates with quality of work life, occupation, emotional, social relationships as well as physical wellbeing. There is a need to address the labelling of others via conducting awareness seminars on stuttering and self-perceptions of stuttering people about themselves by acknowledging their stammering, in this way, PWS will receive more favourable ratings about their intelligence, appearance, and personality as compared to those who don't acknowledge stuttering. Managers also need to be more effective and comfortable communicators in the workplace.

\section{A. Limitations and Directions for Future Research}

This study has some several limitations. Firstly, the result of this study are based on limited data collected due to non- availability of access to the intended respondents i.e. stutterers. It is mainly due to strict compliance of the Hospitals which provides speech therapy to their patients. They make it very confident. Snowball method is used which is not authentic. Future researchers may get the data from different sources and for this purpose they required to firstly create awareness among the people in general and stutterers in specific.

\section{Conclusion}

As per the findings of this study, people who have accepted their stuttering actually put their abilities in a positive way and gets the results as per their efforts. This also confirms that SAS people perform their in-role performance. SAS strongly judge their stuttering positively affecting their chances of employment as well as their job performance. They don not present excuses to justify failure in their employment opportunities and job performance because of stuttering. Although, majority of the stuttering people stated their story in one way or other by explaining how this stuttering has stopped their careers but not those who have accepted this stuttering. To eradicate, this perception of people regarding stuttering as a disease /myth, awareness through education about stuttering is very important because when educated, they will start believing less handicapping and acknowledge their stuttering 
favorably. With this stuttering awareness in Pakistan, we can encourage people who stutter to start accepting and believing their capabilities, don't give up and add them as human capital acquisition.

\section{References}

American Speech-Language-Hearing Association. Stuttering. Retrieved June 25, 2009 from http://www.asha.org/public/speech/disorders/stuttering.htm

Ardila, A., Bateman, J. R., Nino, C. R., Pulido, E., Rivera, D. B., \& Vanegas, C. J. (1994). An epidemiological study of stuttering. Journal of Communication Disorders, 27, 37-48.

Arnold, K.A., Turner, N., Barling, J., Kelloway, E.K., \& McKee, M.C. (2007). Transformational leadership and psychological well-being: The mediating role of meaningful work. Journal of Occupational Health Psychology, 12 (3), Jul., 193-203.

Avolio, B. J., \& Bass, B. M. (1995). Individual consideration viewed at multiple levels of analysis: A multilevel framework for examining the diffusion of transformational leadership. The Leadership Quarterly, 6, 199-218.

Ashkanasy, N. M., \& Hooper, G. S. (1999). Perceiving and managing emotion in the workplace: A research agenda based on neurophysiology.Australian Journal of Psychology, 51(Supplement 1999), 51.

Babin, B. J., \& Boles, J. S. (1996). The effects of perceived co-worker involvement and supervisor support on service provider role stress, performance and job satisfaction. Journal of retailing, 72(1), 57-75.

Bandura, A. (1977). Self-efficacy: toward a unifying theory of behavioral change. Psychological review, 84(2), 191.

Bandura, A. (1997). Self-efficacy: The exercise of control.

Bandura, A. (2001). Social cognitive theory: an agentic perspective. Annual Review of Psychology, 52(1), 1-26.

Bass, B. M. (1985). Leadership and performance beyond expectations. New York: Free Press.

Bloodstein, O., \& Bernstein Ratner, N. (2008). A handbook of stuttering (6th ed.). New York: Thomson Delmar Learning.

Borman, W. C., \& Motowidlo, S. J. (1997). Task performance and contextual performance: The meaning for personnel selection research. Human performance, 10(2), 99-109.

Boyle, M. P. (2015). Relationships between psychosocial factors and quality of life for adults who stutter. American Journal of Speech-Language Pathology, 24(1), 1-12.

Bricker-Katz, G., Lincoln, M., \& Steven. C. (2013). Stuttering and work life: An interpretative phenomenological analysis. Journal of Fluency Disorders, 38, 342-355

Carver, C. S., Scheier, M. F., \& Weintraub, J. K. (1989). Assessing coping strategies: a theoretically based approach. Journal of personality and social psychology, 56(2), 267.

Casier, A., Goubert, L., Theunis, M., Huse, D., De Baets, F., Matthys, D., \& Crombez, G.(2011). Acceptance and well-being in adolescents and young adults with cystic fibrosis: a prospective study. Journal of pediatric psychology, jsq111.

Chen, G., Gully, S. M., \& Eden, D. (2001). Validation of a new general self-efficacy scale. Organizational research methods, 4(1), 62-83.

Chen, G., Casper, W. J., \& Cortina, J. M. (2001). The roles of self-efficacy and task complexity In the relationships among cognitive ability, conscientiousness, and work- 
Pakistan Journal of Humanities and Social Sciences, 7(3), 2019

related performance: A meta-analytic examination. Human Performance, 14, 209230.

Craig, A. (2010). Smooth speech and cognitive behaviour therapy for the treatment of older children and adolescents who stutter. In B. Guitar, \& R. McCauleyr (Eds.), Treatmentof stuttering: Established and emerging interventions (pp. 188-214). Baltimore: Lippincott Williams \& Wilkins.

Daniels, D.E. (2008). Working with people who stutter of diverse cultural backgrounds; some ideas to consider. Perspectives on Fluency and Fluency Disorders, 8, 95-100.

De Nardo, T., Gabel, R. M., Tetnowski, J. A., \& Swartz, E. R. (2016). Self-acceptance of stuttering: A preliminary study. Journal of communication disorders, 60, 27-38.

DeLoach, C., \& Greer, B. G. (1981). Adjustment to severe physical disability: A metamorphosis. McGraw-Hill Companies.

Frattali, C. (1998). Measuring modality-specific behaviours, functional abilities, and quality of life. In C. Frattali (Ed.). Outcome measurement in speech-language pathology (pp. 55 88). New York: Thieme Medical Publishers.

Folkman, S. (1997). Positive psychological states and coping with severe stress. Social Science \& Medicine, 45(8), 1207-1221.

Garcia, L. J., Laroche, C., \& Barette, J. (2002).Work integration issues go beyond the nature of communication disorder. Journal of Communication Disorders, 35, 187-211.

Gist, M.E. and Mitchell, T.R. (1992). Self-efficacy: a theoretical analysis of its determinants and malleability. Academy of Management Journal, 17(2), 183-211.

Goodman, S. A., \& Svyantek, D. J. (1999). Person-organization fit and contextual performance: Do shared values matter. Journal of Vocational Behavior, 55(2), 254275.

Graen,G. (1976). Role-making processes within complex organizations. Handbook of industrial and organizational psychology, 1201, 1245.

Griffin, M. A., Neal, A., \& Parker, S. K. (2007). A new model of work role performance: Positive behavior in uncertain and interdependent contexts. Academy of Management Journal, 50(2), 327-347.

Guitar, B. (2013). Stuttering: An integrated approach to its nature and treatment. Lippincott Williams \& Wilkins.

Hale, C. J., Hannum, J. W., \& Espelage, D. L. (2005). Social support and physical health: The importance of belonging. Journal of American College Health, 53(6), 276-284.

Hurst, M. I., \& Cooper, E. B. (1983). Employer attitudes toward stuttering. Journal of Fluency Disorders, 8(1), 1-12.

Isaksson, G., Josephsson, S., Lexell, J., \& Skär, L. (2007). To regain participation in occupations through human encounters-narratives from women with spinal cord injury. Disability and Rehabilitation, 29(22), 1679-1688.

Kark R, Shamir B, Chen G. (2003). The two faces of transformational leadership: Empowerment and dependency. Journal of Applied Psychology, 88, 246-255.

Keany, K., \& Glueckauf, R. (1993). Disability and value change: an over view and reanalysis of acceptance of loss theory. Rehabilitation Psychology, 38(3), 199-210.

Kirkpatrick, S. A., \& Locke, E. A. (1996). Direct and indirect effects of three core charismatic leadership components on performance and attitudes. The Journal of Applied Psychology, 81, 36-51.

Klein, F. J., \& Hood, B. S. (2004). The impact of stuttering on employment opportunities and job performance. Journal of Fluency Disorders, 29 (2004), 255-273.

Lazarus, R. S., \& Folkman, S. (1984). Stress, appraisal, and coping. Springer publishing company. 
Li, L., \& Moore, D. (1998). Acceptance of disability and its correlates. The Journal of social psychology, 138(1), 13-25.

Luthans, F., Avolio, B.J., Avey, J.B. and Norman, S.M. (2007). Positive psychological capital: measurement and relationship with performance and satisfaction. Personnel Psychology, 60(3), 541-572.

Malecki, C. K., \& Demaray, M. K. (2003). What Type of Support Do They Need? Investigating Student Adjustment as Related to Emotional, Informational, Appraisal, and Instrumental Support. School psychology quarterly, 18(3), 231.

Menzies, R. G., Onslow, M., \& Packman, A. (1999). Anxiety and stuttering: Exploring a complex relationship. American Journal of Speech-Language Pathology, 8(1), 3.

Nielsen, K., Yarker, J., Randall, R., \& Munir, F. (2009).

Pajares, F. (2002). Overview of social cognitive theory and of self-efficacy. Retrieved March, 10, 2008, from http://www.emory.edu/EDUCATION/mfp/eff.html

Perkins, W. H. (1993). The early history of behavior modification of stuttering: A view from the trenches. Journal of Fluency Disorders, 18, 1-11.

Plexico, L., Manning, W. H., \& Levitt, H. (2009b). Coping responses by adults who stutter: Part II. Approaching the problem and achieving agency. Journal of fluency disorders, 34(2), 108-126.

Prins, D. (1993). Models for treatment efficacy studies of adult stutterers. Journal of Fluency Disorders, 18, 333-349.

Rees, I. D., \& Sabia, J. J. (2014). The kid's speech: The effect of stuttering on human capital acquisition. Economics of Education Review, 38, 76-88.

Riketta, M. (2002). Attitudinal organizational commitment and job performance: a meta-analysis. Journal of organizational behavior, 23(3), 257-266.

Rogers, C. R., \& Carmichael, L. (1942). Counseling and psychotherapy: Newer concepts in practice. Boston: Houghton Mifflin.

Schulz, R., \& Decker, S. (1985a). Long-term adjustment to physical disability: the role of emotional support, perceived control, and self-blame. Journal of Personality and Social Psychology, 48(5), 1162.

Schulz, R., \& Decker, S. (1985b). Long-term adjustment to physical disability: the role of social support, perceived control, and self-blame. Journal of personality and social psychology, 48(5), 1162.

Shamir, B., House, R. J., \& Arthur, M. B. (1993). The motivational effect of charismatic leadership: A self-concept based theory. Organization Science, 4, 577-594.

Shapiro, D. A. (1999). Stuttering intervention: A collaborative journey to fluency freedom. Pro Ed.

Sheane, S. D. (2012). Putting on a good face: An examination of the emotional and aestheticroots of presentational labour. Economic and Industrial Democracy,33(1), $145-158$.

Sheehan, J.G., \& Martyn, M. M. (1970). Stuttering and its disappearance. Journal of Speech and Hearing Research, 9, 121-135

Sosik, J. J., \& Godshalk, V. M. (2000). Leadership styles, mentoring functions received, and job-related stress: a conceptual model and preliminary study. Journal of Organizational Behavior, 21(4), 365-390.

Stajkovic, A.D. and Luthans, F. (1998). Self-efficacy and work-related performance: a metaAnalysis. Psychological Bulletin, 124(2), 240-261.

Swartz, E., Irani, F., \& Gabel, R. (2014). Coping with stuttering. SIG 4 Perspectives on Fluency and Fluency Disorders, 24(2), 58-68. 
Pakistan Journal of Humanities and Social Sciences, 7(3), 2019

Tims, M., Bakker, A. B., \& Xanthopoulou, D. (2011). Do transformational leaders enhance their followers' daily work engagement?. The Leadership Quarterly, 22(1), 121-131.

Tzonichaki, L., \& Kleftaras, G. (2002). Paraplegia from spinal cord injury: Self-esteem, loneliness, and life satisfaction. OTJR: Occupation, Participation and Health, 22(3), 96-103.

Van Riper, C. (1982). The nature of stuttering (2nd ed.). Prentice-Hall: Englewood Cliffs, N.J.

Welbourne, T. M., Johnson, D. E., \& Erez, A. (1998). The role-based performance scale: Validity analysis of a theory-based measure. Academy of management journal, 41(5), 540-555.

Williams, L. J., \& Anderson, S. E. (1991). Job satisfaction and organizational commitment as predictors of organizational citizenship and in-role behaviors. Journal of management, 17(3), 601-617.

Wingate, M.E.(1964).Recovery from stuttering. Journal of Speech and Hearing Disorders, 29, 312-321.

Wong, C. S., \& Law, K. S. (2002). The effects of leader and follower emotional intelligence on performance and attitude:An exploratory study. The leadership quarterly, 13(3), 243-274.

Xanthopoulou, D., Bakker, A. B., Demerouti, E., \& Schaufeli, W. B. (2007). The role of personal resources in the job demands-resources model. International Journal of Stress Management, 14, 121-141.

Yaruss, J. S., \& Quesal, R. W. (2004). Stuttering and the international classification of functioning, disability, and health (ICF): An update. Journal of Communication Disorders, 37, 35-52.

Yaruss, J. S., \& Quesal, R. W. (2010). OASES: Overall assessment of the speaker's experience of stuttering. Bloomington MN: Pearson Assessments.

Yukl, G. (1989). Managerial leadership: A review of theory and research. Journal of Management, 15(2), 251-289.

Zimet, G. D., Dahlem, N. W., Zimet, S. G., \& Farley, G. K. (1988). The multidimensional scale of perceived social support. Journal of personality assessment, 52(1), 30-41. 